\title{
Accounting Information Systems in an Open Society. Emerging Trends and Issues
}

\author{
Daniela Mancini*
}

\begin{abstract}
During the second decade of the XXI century, several contextual forces have changed the way in which firms interact with environment. The economic and financial crisis, the development of technologies, the convergence between different communication channels and the spread of social networks are just some of the forces that determine a quick and radical change in the way employees and firms look at the future and interact each other.

This contribution focuses on the meaning of the word "open” as one of the keywords of this period and highlights how the open society affects accounting information systems, as systems processing information to support strategic decisions in such a complicated environment.
\end{abstract}

Keywords: accounting information systems, open society.

\section{Introduction}

Searching for an innovative response to the economic and financial crisis, governments, companies, and people have been adopting new rules, new business models, new tools to manage the relationship with the environment. Web 2.0 technologies provided useful tools to generating, sharing and refining information as social networks, wikis, tags, etc. Moreover, cultural issues and privacy needs, arising from the spread of internet technology, have stirred up new rules, forms of tutorship and protection in order to safeguard privacy and, at the same time, to not cutting the great potential of connectivity and its applications. Furthermore, the increasing relevance of ethical principles and issues related to non-ethical behaviours have stimulated the promulgation of some laws to encourage transparency in private and public sectors leveraging digital and web technologies.

Regarding companies, all these forces draw the attention on data, infor-

* Università degli Studi di Napoli Parthenope, Dipartimento di Studi Aziendali ed Economici. E-mail: mancini@uniparthenope.it. 
mation and accounting information systems and their capability in facilitating relevant and reliable decision-making processes, inside and outside (Mancini et al., 2013). Technological innovations and regulations have deeply changed the way in which firms and their managers process and share accounting information and interact each other, promoting the use of websites, social networks and collaborative platforms.

Thanks to technological innovations, traditional software, able to support performances measurement, or to manage accounting and control processes are used in workplaces characterized by a shared and fluid circulation of information. National and international institutions issued rules and laws to stimulate changes in information management practices, in private as well as in public context, in order to stimulate efficiency, cost reduction and transparency. In some cases the adoption of these regulations required the implementation of specific technological tools (i.e. electronic invoicing, XBRL, digital platforms, web portals, etc.) (Fradeani, 2005; Bellini et al., 2015).

In recent years, one of the most cited adjectives in academic and professional studies, and in social networks posts is 'open'. It is very common to hear about open education, open knowledge, open innovation, open source, open data, open government, open access, open day, open book accounting. This is because some different forces acted for the spreading of an open society and we are moving to live in an open society.

According to the Oxford Dictionary, the word 'open' may be used in different meanings. It concerns something that allows access, passage and view through an empty space; something without barriers all around and not covered in or over; something that is public, not restricted to specific category of people, or free from charges and something that is vulnerable or damaged. In this sense, it is clear that the word can have a meaning either positive or negative: if something is open, it can picks up or offers many opportunities, but it can also be vulnerable to threats. Further, this word indicates that opportunities and threats are linked to transparency that comes from being open.

In the era of Internet and social networks the adjective 'open' have a deep and complex meaning based on a contamination of different fields of knowledge and life experiences. The word open is related to technology, to social, to sharing, to freedom, to transparency. It sounds as a democratic concept.

Some questions emerge if we consider the impact of open philosophy on the accounting environment, and if we consider how digital technologies affect accounting models, accounting information systems, and other rele- 
vant mechanisms (management control systems, performance measurement systems, internal control systems, cost management techniques, risk assessment and risk management systems, etc.). What role companies' information system plays in an open society? What are its main features? What are the implications of the open philosophy for accounting models design and control systems? What are risks that emerge in this scenario? What are the changes in the settled practices, expertise and skills? What are the effects for firms? What are the actors involved?

This issue of Management Control journal contains a selection of papers presented at SIDREA International Workshop "Information Systems in an Open Society: Emerging Trends and Issues”, which was held at Parthenope University of Naples on $17^{\text {th }}-18^{\text {th }}$ September 2016. The objective of the Workshop was to promote a debate on challenges and threats for accounting information and control systems in an open society.

The remainder of the contribution is organised as follows: the next section explores the main features of the open movement and their implications on accounting information systems and accounting environment, the last section analyses the paper selected in light of the previous considerations.

\section{Open-something: what is new?}

As highlighted in the previous section, today the word 'open' has a particular meaning related to digitalization, socialization, sharing. Regardless from the noun to which it is related, the meaning of this adjective revolves around some key aspects. In this paragraph, we examine the meaning of the word 'open' analysing different field of research and highlighting its meaning in business.

\subsection{Enterprise 2.0}

Scholars focus the attention on a broader vision of firms, known as Enterprise 2.0, in which companies based their competitive advantage on the use of digital technologies and their ability to support knowledge workers, facilitating collaboration, interaction and knowledge sharing.

Openness in this case is connected to a different way to conceive work between organisational units, within and between organisations, based on a growing importance of collaboration and social networking. Web 2.0 technologies, as groupware, intranet and digital platforms, provide not prede- 
fined systems able in supporting interactivity, quick responses, social connectivity (Hawryszkiewycz, 2010).

In order to activate collaboration and sharing, companies need a broader vision of their business on which they have to build a collaborative architecture and a collaborative infrastructure. The first identifies roles and organisational units that companies use as collaborative solutions. The second is the technology infrastructure that companies use to support collaborative work. It consists in a wide range of platforms (intranet, corporate web site or information portals) able to improve a more efficient and effective communication, between knowledge workers, than the traditional channels (emails and instant messaging) (McAfee, 2006). Enterprise 2.0 technologies offer, usually, six powerful tools to search and quickly categorize any content: a) search information according users' needs using custom keywords; b) define information relevance through a dense link structure among pages built by many users; c) let people authoring contents in an incremental and iterative way through blogs or wikis; d) allow users to autonomously categorize information attaching tags as short description of contents they consult; e) suggest extentions as recommended subjects homes in on users tastes; f) use signals to aggregate notices on new contents of interest for people.

Two important features characterise these platforms:

1) They are easy to use because the main functionalities "can be done nothing more than a Web browser, a few clicks and some typing" (McAfee, 2006).

2) They are not preconceived and structured, and users can influence their structure from the start combining multi-layers of devices, network, contents and service with no fixed boundaries (Jackson, 2015).

In this field of research, scholars stressed particularly the contribution of technology and Web 2.0 tools in creating an open infrastructure through which companies can develop their collaborative environment. Compared to the past, the difference is that these tools are user-centred and take a specific shape through the interaction and the contribution of users (Corsi, Mancini, 2016).

\subsection{Open Data and open governance}

In the public sector the expression 'open data' regards "any content, information or data that people are free to use, re-use and redistribute, without any legal, technological or social restriction” (OKFN, 2016). In this field of research openess is based on three key concepts (Ponte, 2015; Maccani et al., 2015; Laine et al. 2015): 
1) availability of data and free access;

2) sharing and re-use of data;

3) universal participation in term of subjects (full inclusion and no restriction to a group of people), time and space (anywhere) and aims (any purpose).

Information have to flow free and without restrictions among organisations or groups of people. Data and information have to be organised and managed to facilitate sharing and re-using. The theme of open data is also connected to other two keywords: open-government and transparency. The first concerns the use of ICT to enhance government, public accountability and citizen participation. The second identifies some features of data and information necessary to ensure an open government in the age of Internet. In fact, Internet is considered a fundamental mean to ensure transparency, but in order to improve accountability the publication of information is not enough. Public institution must also assure information accessibility, effectiveness, usability, and interactivity (Mancini, Lamboglia, 2016). Open data is even important because of the economic impact that it can produce, in fact information can be reused, especially for commercial purpose, and can be used to interpret complex events.

In this context, scholars stressed data and information, and the requirements that they assume in an open environment. Compared to the past what is considered new is that information have to be largely public and free, accessible to everyone.

\subsection{Open Innovation, open education and open knowledge}

Open innovation is a way to manage the innovation process based on corporate partnering, various form of collaboration and external sourcing of R\&D activities. Thanks to Web 2.0 applications, companies can effectively manage their innovation processes involving different actors as customers, suppliers or partners. The success of open innovation depends on several factors, in fact technological tools are only a means through which companies have to engage partners, manage and stimulate their participation (Castriotta, Di Guardo, 2011). Moreover, companies that base their innovation process on openness, have to understand what are the possible, desirable and affordable types of partnership, and under what conditions they are profitable.

Scholars investigate the secrets and the success factors of these open communities of co-creation. Transparency is one of the key features: it regards the process through which innovative ideas are collected and evaluat- 
ed, the response and the explanation of their feasibility. Another key success factor is the "remuneration" for the participation to an open innovation process. It can consist in gratification rising from new skills acquisition, knowledge sharing, etc. At last open innovation is based on a key principle: "the continuous exchange of ideas, knowledge, information, needs inside an actors' network to produce a form of "cooperative intelligence" (Capriglione et al., 2011).

In this field of research, scholars stressed the fact that collaboration can play a pivotal role in the innovation process. In order to activate this synergy some key elements are necessary: Web 2.0 technology, as a mean; transparency and non-financial remuneration, as urge to co-creation and cooperative intelligence (Ming Lee Wen, Tze-Chang, 2016).

Even in the field of open education, the word open refers to the use of ICT to make learning and knowledge more cooperative than the past. Open education aims to allow teachers and students to perform their activities anywhere, anytime and by anyway and also to share their knowledge and create together new knowledge.

In this sense, technology is not only a fundamental tool able to support teaching and learning, but it has also social and political implication. In fact, thanks to the ubiquitous technology, education and knowledge comes from the interaction and the collaboration between several actors and becomes really inclusive, fair and open to diversity.

\section{Open accounting information systems: from integration to sharing}

In previous sections, we described some of the various nuances of openness concept and these help us to identify the boundaries of that concept and its relationship with information technologies and information systems.

In our opinion, openness introduces a new way to understand "why", "how" and "what" of accounting information systems. It is clear that an open system bases its activity and success on the following elements:

1. An electronic infrastructure as a mix of integrated tools able to connect in an interactive way internal efforts of employees and external contribution of customers, partners, and suppliers;

2. Data and information availability, sharing and re-use;

3. Co-creation of knowledge, ideas, meanings, etc. through interaction, collaboration and inclusiveness.

Considering these elements from the accounting information systems point of view, we can notice a fundamental change in the concept of 
integration. In the past, integration was regarded as a technological concept, involving computer and other hardware devices, in order to reach a higher level of efficiency and cost reduction in data processing. Later, the attention focused on integration of information, databases and processes, in order to improve information system effectiveness (Marchi, 2003; Dechow, Mouritsen, 2005). Nowadays, integration regards people and means the sharing and exchange of information, feedback, ideas, suggestions, opinions between people, inside and outside companies, in order to create value by interaction and redeploy the value created from an interaction to another (Bughin, Chui, 2010).

\section{Paper in this issue}

Articles published on this issue are a selection of five papers presented at SIDREA International Workshop "Information Systems in an Open Society: Emerging Trends and Issues". It also includes a research of the invited speaker Prof. Joshua Onome Imoniana from Sao Paulo University, concerning the implications of digital technologies on auditor skills and assurance work.

The first tree contributions regard information systems in business networks, the forth concerns the impact of integration on accounting information systems while the last is on strategic intelligence. In general, the papers reveal that the study of accounting information systems in an open context is at an embryonic stage and further research are necessary. Each paper focuses on particular aspects and uses specific research methodologies worthy of attention.

The first tree papers interpret openness as the collaboration that companies develop as a competitive lever. The phenomenon of alliances and collaborations is particularly significant in Italy because the law 122/2010, introduced the network contract (Cardoni, 2012; Massaro et al., 2012; Caputo et al., 2014). Those papers discuss an important issues for business networks investigating performance measurement in different context (small and medium firms, health services, inter organisational networks) and its relation with information technology.

The work of Aureli and Del Baldo, focuses on performance in business networks created by small and medium enterprises. Adopting a qualitative methodology, network-level perspective, the authors investigate how performance are measured and how partners use information system to collect and disseminate information. Although a part of the literature suggests the 
use of digital technologies to manage measurement models, considering five case of Italian networks, the results show that traditional financial (sales, profit, ROI, ROE, etc.) and quantitative (number of new customers, time saving, etc.) performance are more considered than innovation and learning perspective or internal and business perspective. Moreover, several traditional tools are used to collect data and information such as meetings, internal reports and rarely budgets. Information and communication technologies infrastructure is not very structured, is not yet considered as a pivotal mean. In fact traditional tools as spreadsheets, emails, communication platforms (Skype and WhatsApp) are used to manipulate data regarding network performance, and to share and discuss in a formal or informal way. While electronic mailing, social media and web site are used to manage the relationship with clients.

The work of Angiola and Bianchi, focuses on performance appraisal in public/private networks with regard to home care integrated services for eldery. Considering the case of Apulia Region, authors developed a survey, based on 272 interviews, to investigate how performance, in term of integration/coordination of services, are perceived by politicians, managers and directors, and what kind of factors influence network effectiveness. Results show that, according to the perception of interviewers, the level of integration is very different within Apulia Region and, among the independent variables considered in the regression model, information systems and organisational well-being are significant. Even if, according to network performance literature, the information system plays a pivotal role in Apulia public/private network, it is not integrated and information are not consistent and shared. According the authors, to improving integrated services, collaboration among local welfare areas and health district is fundamental and for this issue information systems could represent a great opportunity in public administration to shift into a more integrated and shared context than the past and to help a change of mindset.

Rizza and Ruggieri investigate how accounting information systems can facilitate the purchasing process, in particular the suppliers' selection. Considering a longitudinal case study of an Italian firm, authors examine how the reconfiguration of the purchase process and the rethinking of SAP interface and reports affected suppliers' selection (quality, delivery time and related costs). SAP becomes a platform around which different actors interact to manage and share data, information, activities, reports and performance in order to assure a more effective and efficient purchase process. According the authors, SAP represents not only a technological infrastructure but also a space where diverse purchase areas and every supplier "ac- 
tively participated to socially construct the reality [...] suggest some improvements in the performance reports [...] whereas they interacted sharing accounting information”.

The work of Sara Trucco investigates the impacts of an integrated information system on managerial accounting. Adopting an accounting managers perspective, the author explores controllers and financial accountants perception of managerial information quality as a consequence of the use of an integrated information technology system and an overall integration of accounting systems. Results confirm that, for Italian accounting managers, IT integration allows for more timely and reliable information, and convergence of financial accounting and management accounting generates some benefits for managers and firms.

Despite the growing attention on Intelligence, most literature neglects its implication on information systems. Starting from this research gap Galeotti, Garzella, Fiorentino, della Corte develop a conceptual framework on Strategic Intelligence and suggest "sources and methods to translate data into effective knowledge for strategic decision-making". The authors propose a five-dimensional framework, which request an advanced concept of integration of information systems. In fact, strategic intelligence implies the integration between intelligent data, information systems and methods for searching, collecting, processing, interpreting data in order to translate them into new strategic ideas, decision and action. This broadest concept of integration requires the usage of opportunities coming from the Internet, and the extension of IT tools to all processes and critical resources that interactively sustain company's strategic decisions.

Finally, the work of Imoniana and Perera investigates implications of digital technologies (as clouds, mobile applications, digital devices, ecommerce, online purchasing and e-banking) on audit quality. Authors also examine the role of information systems auditors in a digital environment; evaluate types and levels of knowledge and expertise required to financial auditors in auditing companies that use digital technologies. Results highlight a research gap in examining topics to be included in university curriculum for IS/IT auditors and in issues related to IT security, audit trail, transaction recording.

\section{Conclusions and further research}

This issue contributes to the discussion in a young research field as the adoption of open and digital technologies in information systems, with par- 
ticular attention to the accounting environment. In this field, contributions are still fragmented and in an exploratory phase. They try to discover, often through case analysis, implications and potentialities of this group of technologies (Resca et al., 2013; Agrifoglio, Metallo, 2011; Mancini, Ferruzzi, 2016). Sometimes, as papers published in this issue, scholars highlight cases and situation where open technologies are required or, if employed, they could contribute to value creation.

Moreover, articles included in the issue ask more research to deepen the relevant and understudied topic of shared and collaborative information systems pointing the attention on three aspects: processes coordination, actors and decisions. From the first aspect, crucial questions are how generative technologies can contribute to performance measurement in business networks, in what way can ameliorate collaboration and network effectiveness in public/private partnerships, and how those technologies can be adopted to manage operational process and improve interfirm relationship. Regarding actors, articles identify accounting managers' perception as a key aspects to investigate for spreading these technologies inside companies together with their integration with managerial information. Regarding decisions, a relevant question is how internet technology can boost strategic intelligence. In particular, contributions are able to draw the attention on the transition from integrated accounting information systems to shared accounting information systems.

More generally, research might be needed to discover what, how and why open technologies, because of their generativity, can be adopted to better manage accounting information in supporting decision making processes.

\section{References}

Agrifoglio R., Metallo C. (2011), Virtual Environment and Collaborative Work: the Role of Relation Quality in Facilitating Individual Creativity, in: D’Atri A., Ferrara M., George J.F., Spagnoletti P. (eds.), Information Technology and Innovation Trends in Organizations, Heidelberg, Springer-Verlag.

Bellini F., D’Ascenzo F. (2015), Evaluation of the e-Invoicing Impacts through a set of Key Performance Indicators, Management Control 3, pp. 9-21.

Doi: 10.3280/MACO2015-003002.

Bughin J., Chui M. (2010), The rise of the networked enterprise: Web 2.0 finds its payday, McKinsey Quarterly, December.

Capriglione A., Casalino N., Draoli M. (2011), Relational Networks for the Open Innovation in the Italian Public Administration, in D’Atri A., Ferrara M., George J.F., Spagnoletti P., Information Technology and Innovation Trends in Organizations, Physica-Verlag. 
Caputo F., Livieri B., Venturelli A. (2014), Intangibles and Value Creation in Network Agreements: analysis of italian firms, Management Control, Special Issue 2, pp. 45-70. Doi: 10.3280/MACO2014-002003.

Cardoni A. (2012), Business planning and management accounting in strategic networks: theoretical development and empirical evidence from enterprises' network "agreement”, Management Control, Suppl. 3, pp. 91-116.

Doi: 10.3280/MACO2012-00SU3005.

Castriotta M., Di Guardo M.C. (2011), Open Innovation and Crowdsourcing: the Case of Mulino Bianco, in D’Atri A., Ferrara M., George J.F., Spagnoletti P., Information Technology and Innovation Trends in Organizations, Physica-Verlag.

Corsi K., Mancini D. (2015), Regulatory compliance of financial control systems and its implications for accountants. Some evidence from Italian experience, Management Control, 3, pp. 65-91. Doi: 10.3280/MACO2015-003005.

Dechow N., Mouritsen (2005), Enterprise resource planning systems, management control and the quest for integration, Accounting Organization Society, vol. 30, issue 7/8, pp. 691-733. Doi: 10.1108/IJOPM-11-2011-0430.

Fradeani A. (2005), La globalizzazione della comunicazione economico-finanziaria. IAS/IFRS e XBRL, Milano, Giuffrè.

Hawryszkiewycz I.T. (2010), A framework for synchronizing collaborative technology with changing enterprise environment, International Symposium on Collaborative Technologies and Systems (CTS), Chicago, IL.

Jackson P. (2015), Networks in a Digital World: A Cybernetics Perspective, European Conference of Information Systems (ECIS), Completed Research Papers, Paper 85.

Laine S., Lee C., Nieminen M. (2015), Trasparent Data Supply for Open Information Production Process, Twenty-Third European Conference on Information Systems (ECIS), Munster, Germany.

Maccani G., Donnellan B., Helfert M. (2015), Exploring the Factors that Influence the Diffusion of Open Data for New Service Development: an Interpretative Case Study, Twenty-Third European Conference on Information Systems (ECIS), Munster, Germany.

Mancini D. (2011), L'azienda-rete e le decisioni di partnership: il ruolo del Sistema informative relazionale, Management Control, 1, pp. 65-97.

Doi: 10.3280/MACO2011-001004.

Mancini D., Corsi K (2016), Management control systems and use of digital platforms: a multi case study comparison, International Journal of Auditing Technology, (forthcoming).

Mancini D., Ferruzzi C. (2016), Using collaboration platforms for management control processes: new opportunities for integration, in Torre T., Braccini A.M., Spinelli R., Empowering Organizations. Enabling Platforms and Artefacts, LNISO, Springer International Publishing, n. 11.

Mancini D., Lamboglia R. (2016), Accounting information system and transparency: a theoretical framework, in Corsi K., Castellano N., Lamboglia R., Mancini D., Reshaping accounting and management control system through digital innovation. New opportunities from business information systems, LNISO, Springer International Publishing (forthcoming).

Mancini D., Vaassen E.H.J., \& Dameri R.P. (2013), Trends in accounting information systems, in Mancini D., Vaassen E.H.J., \& Dameri R.P. (Eds.), Accounting Information Systems for Decision Making, LNISO, Heidelberg, Springer Verlag.

Marchi L. (2011), L'evoluzione del controllo di gestione nella prospettiva informative e gestionale esterna, Management Control, 3, pp. 5-16.

Doi: 10.3280/MACO2011-003001. 
Massaro M., Moro A., Lucas M. (2012), Approcci formali e informali al controllo negli innovation network. La relazione tra leve del controllo e fattori della fiducia, 1, pp. 2754. Doi: 10.3280/MACO2012-001003.

McAfee A.P. (2006), Enterprise 2.0: The Dawn of Emergent Collaboration, MITSloan Mangement Review, Spring, vol. 47, n. 3.

Ming Lee Wen S., Tze-Chang Liu (2016), Reconsidering teachers' habits and experiences of ubiquitous learning to open knowledge, Computers in Human Behaviour, n. 55.

Open Knowledge Foundation (2016), http://okfn.org/opendata/, http://opendefinition.org/od/2.1/en/.

Ponte D. (2015), Enabling an Open Data Ecosystem: Preliminary Findings, From the Market, Twenty-Third European Conference on Information Systems (ECIS), Munster, Germany.

Resca A., Za S. and Spagnoletti P. (2013), Digital Platforms as Sources for Organizational and Strategic Transformation: A Case Study of the Midblue Project, Journal of Theoretical and Applied Electronic Commerce Research, Vol. 8, No. 2,

Verganti R., Pisano G.P. (2008), Which Kind of Collaboration Is Right for You?, Harvard Business Review, 86, no. 12. Doi: 10.1108/sd.2009.05625dad.001. 